\title{
Considerations for applying metabolomics to the analysis of extracellular vesicles
}

\author{
Laura Palomo ${ }^{1}$, Enriqueta Casal ${ }^{1}$, Felix Royo ${ }^{1,2}$, Diana Cabrera ${ }^{1}$, Sebastiaan van-Liempd ${ }^{1}$ and \\ Juan M. Falcon-Perez ${ }^{1,2,3}$ *
}

'Metabolomics Unit and Platform, Center for Cooperative Research in Biosciences (CIC bioGUNE), Derio, Spain

${ }^{2}$ Centro de Investigacion Biomedica en Red de Enfermedades Hepaticas y Digestivas (CIBERehd), Madrid, Spain

${ }^{3}$ Ikerbasque, Basque Foundation for Science, Bilbao, Spain

${ }^{*}$ Correspondence: jfalcon@cicbiogune.es

Edited by:

Matías Sáenz-Cuesta, Biodonostia Health Research Institute, Spain

Reviewed by:

Shivani Sharma, University of California Los Angeles, USA

Keywords: extracellular vesicles, exosomes, microvesicles, metabolomics, metabonomics, protocol standardization

Cell-derived extracellular vesicles (EVs) are involved in the development of different pathologies including inflammatory diseases and cancer (1) and have demonstrated a promising potential for human diagnostic (2) and therapeutic applications (3). Constitutive secretion of these vesicles has been described for platelets, reticulocytes, dendritic cells, lymphocytes, mast cells, intestinal epithelial cells, adipocytes, and hepatocytes among others (4). In addition, EVs have been isolated from many body fluids including bile (5), blood (6), and urine $(7,8)$, which indicates that they can be systemically disseminated, transferring their content/signals to cells physically separated from the secreting cell. Depending mainly on the vesicle's origin and the way of vesicle-discharge from the cells, at least two types of EVs have been described: the endosome-derived vesicles named "exosomes" and the plasma membrane shedding vesicles referred to as microparticles. Microparticles are a heterogeneous population of vesicles with a size up $1000 \mathrm{~nm}$, this group consists of vesicles that are formed directly from plasma membrane by so-called reverse budding through membrane protrusion and fission (9). Exosomes, on the other hand, are a more homogeneous vesicle population with a size of 30-150 nm and an endocytic origin. They are formed by inward budding of the membrane of an endocytic organelle named multivesicular body and released to the extracellular space by fusion of this organelle with the plasma membrane (9).

The content of EVs and their biological function depend on the cell-type origin. In addition to lipids $(10,11)$ and proteins $(10$, $11)$, EVs give also refuge to mRNA, small RNAs including miRNA (12-17), mtDNA (18), and even genomic DNA (19). It is important to highlight that this material could be incorporated during the budding process of EVs in which a portion of cytosol is also engulfed into the vesicles (20) by controlled mechanisms $(21,22)$. In the process of their formation, cytosolic small molecules (metabolites) such as sugars, amino acids, nucleotides, different enzymatic cofactors, or redox regulatory molecules among others are also included into the vesicles. However, data regarding metabolites associated with EVs are still very limited and therefore extensive work in this is necessary in this area. This research effort is not only needed to map the metabolome of EVs from different origins but also to elucidate whether there are specific mechanisms at play for loading predestined metabolites into specific vesicles.

Extracellular vesicles are widely studied in order to better understand their physiological and pathological role as well as to identify potential non-invasive biomarkers (23). Recent research indicates that EVs have an important effect on the development and progression of diseases such as cancer (24) or immunological (25) diseases. Some of the mechanisms of action responsible for these effects are starting to be unraveled. Remarkably, some publications have demonstrated the involvement of EVs in the metabolic regulation of the extracellular space. In this context, EVs derived from cancer cells are able to modify and educate the microenvironment to facilitate tumor growth and the establishment of metastasis $(26,27)$. The importance of EVs in keeping the normal homeostasis in the neuronal environment is demonstrated by the implication of EVs in the development of Alzheimer and prion-related diseases (28). Clayton and collaborators have showed that EVs modify the extracellular adenosine levels, which has important implications for the activation of the immune system (29). Taking into account the fact that EVs from different cellular origins and with different activities can co-exist in a determined environment and condition, it is clear that these recent studies only reveal the "tip of the Iceberg." It is therefore important to elucidate the function of EVs in other cellular systems to understand the complex EV network, which will influence the final outcome of a determined stimulus or biological process. In the case of hepatocyte-derived EVs, a comprehensive proteomic analysis revealed the presence of proteins involved in metabolizing lipoproteins, endogenous compounds, and xenobiotics, which suggests a role of exosomes in the metabolism of these molecules (30). Our proteomics analysis identified more than 100 different proteins with the potential to modify the extracellular space. These include glycolytic enzymes, fatty acid modifyingenzymes, carboxylesterases, cytochrome P450 monooxygenases (CYPs), and uridine dinucleotide phosphate glucuronosyl transferases (UGTs), among others. The fact that hepatocytes are able to secrete EVs that contain a high number of enzymes 
to extracellular compartments could also suggest that hepatocyte-derived EVs may play a role in the homeostasis of biofluids including blood and bile $(31,32)$.

To elucidate both the metabolome of EVs and the contribution of these vesicles to hepatic and extra-hepatic metabolism, comprehensive technological platforms are needed to integrate the final outcome of the various activities of these vesicles. In this context, the last-up - omic technology, referred as metabonomics or metabolomics, has opened new opportunities to provide a global view of mechanisms and pathways involved in normal physiological processes as well as in the development of diseases. Metabolomics comprises the qualitative and quantitative measurement of the metabolic response to physiological or pathological stimuli. It involves the extraction and measurement of hundreds to thousands of small molecules $(<2000 \mathrm{Da})$ from cells, tissues, or biofluids to generate metabolic profiles (33). Comparisons of such profiles from different genotypes are being used to identify specific metabolic changes leading to the understanding of physiology, toxicology, and disease progression. The recent developments in spectroscopic and separation methods allow for quick and simultaneous measurements of all classes of metabolites in biological samples (33, 34). Advanced bioinformatics and biostatistics can then be used for data mining and modeling. Metabolomic profiling can be performed using a number of analytical techniques including highfield nuclear magnetic resonance (NMR), gas chromatography/mass spectrometry (GC/MS), and liquid chromatography/MS (LC/MS). Despite its excellent inter-lab reproducibility, GCMS requires that the majority of metabolites analyzed need derivatization to provide volatility and thermal stability prior to analysis (35). While NMR demonstrates its advantages in highly selective, quantitative and nondestructive analysis, the sensitivity and therefore the amount of detected metabolites is low compared to MS. LC/MS, while notoriously irreproducible, possesses much higher sensitivity toward most metabolic classes than NMR. Moreover, by using tandem MS in combination with high-resolution spectra, isotope distributions, and ion mobility, identification of unknown metabolites is facilitated. However, due to the before-mentioned irreproducibility chemical standards are normally necessary for absolute metabolite identification. The development of ultra-performance liquid chromatography (UPLC) has made it possible to achieve higher resolutions, higher sensitivities, and rapid separations as compared to those achieved using conventional LC (36).

Moreover, the combination of metabolomics and specialized software devoted to visualize cellular pathways offer a tool to integrate and identify the main mechanisms that trigger a specific biological process. Application of metabolomics is growing rapidly in an increasing range of fields such as biomarker discovery, clinical studies, diagnostics, plants, nutrition, and toxicology $(37,38)$. Furthermore, metabolic biomarkers are expected to be less species dependent than gene or protein markers, facilitating the direct comparison of animal models with human studies (39).

Form a practical point of view, it is important to highlight that for the characterization of the metabolome of EVs additional controls are required that are currently not included in the proteomics and transcriptomics analysis of these vesicles. This is exemplified by the UPLC-MS/MS analysis of exosomes-depleted media that has been incubated in the absence of cells during $72-\mathrm{h}$ at $37^{\circ} \mathrm{C}$, and subjected to the conventional ultracentrifugation method currently used to isolate EVs (40). In these control samples, substantial number of metabolites were detected using conventional solvents to extract metabolites (Figure 1A: $\mathrm{ClCH}_{3}$ :methanol, Figure 1B: methanol). These metabolites are derived from the tissue culture medium and need to

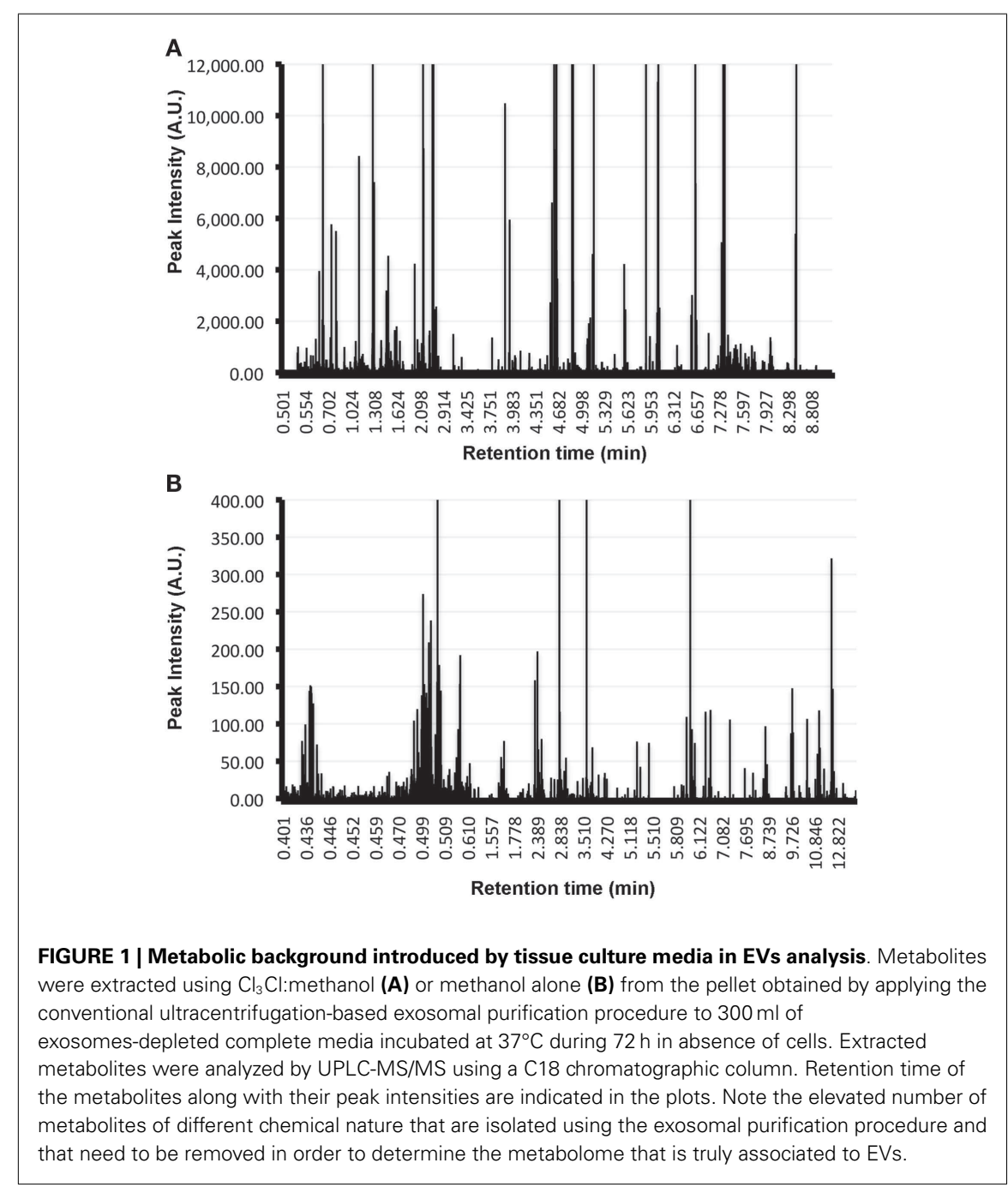


be taking into account and removed from the metabolites detected in the medium that has been conditioned by the cells in order to identify the metabolome truly associated with the EVs of interest. In the case of proteomics and transcriptomics analyses, the background introduced by the tissue culture media can be overcome given that currently tissue culture media used serum from bovine origin as major contributor to the background. Given the species-specific features of proteins and nucleic acids from the media, the contaminating material can be discriminated from the EVs secreted by the cells of interest. An exemption to this latter has to be made if a cell line of bovine origin is used for the production of EVs; in that case a cell free medium incubated under the same conditions is also recommended for proteomics and transcriptomics analyses.

\section{REFERENCES}

1. Anderson HC, Mulhall D, Garimella R. Role of extracellular membrane vesicles in the pathogenesis of various diseases, including cancer, renal diseases, atherosclerosis, and arthritis. Lab Invest (2010) 90(11):1549-57. doi:10.1038/ labinvest.2010.152

2. Simpson RJ, Lim JW, Moritz RL, Mathivanan S. Exosomes: proteomic insights and diagnostic potential. Expert Rev Proteomics (2009) 6(3):267-83. doi:10.1586/epr.09.17

3. Vader P, Breakefield XO, Wood MJ. Extracellular vesicles: emerging targets for cancer therapy. Trends Mol Med (2014) 20(7):385-93. doi:10.1016/j.molmed.2014.03.002

4. Simons M, Raposo G. Exosomes - vesicular carriers for intercellular communication. Curr Opin Cell Biol (2009) 21(4):575-81. doi:10.1016/j.ceb. 2009.03.007

5. Masyuk AI, Huang BQ, Ward CJ, Gradilone SA, Banales JM, Masyuk TV, et al. Biliary exosomes influence cholangiocyte regulatory mechanisms and proliferation through interaction with primary cilia. Am J Physiol Gastrointest Liver Physiol (2010) 299(4):G990-9. doi:10.1152/ajpgi.00093. 2010

6. Bastos-Amador P, Royo F, Gonzalez E, CondeVancells J, Palomo-Diez L, Borras FE, et al. Proteomic analysis of microvesicles from plasma of healthy donors reveals high individual variability. J Proteomics (2012) 75(12):3574-84. doi:10.1016/ j.jprot.2012.03.054

7. Conde-Vancells J, Rodriguez-Suarez E, Gonzalez E, Berisa A, Gil D, Embade N, et al. Candidate biomarkers in exosome-like vesicles purified from rat and mouse urine samples. Proteomics Clin Appl (2010) 4(4):416-25. doi:10.1002/prca. 200900103

8. Perez A, Loizaga A, Arceo R, Lacasa I, Rabade A, Zorroza K, et al. A pilot study on the potential of RNA-associated to urinary vesicles as a suitable non-invasive source for diagnostic purposes in bladder cancer. Cancers (Basel) (2014) 6(1):179-92. doi:10.3390/cancers6010179

9. Raposo G, Stoorvogel W. Extracellular vesicles: exosomes, microvesicles, and friends. J Cell Biol (2013) 200(4):373-83. doi:10.1083/jcb.201211138

10. Kalra H, Simpson RJ, Ji H, Aikawa E, Altevogt P, Askenase P, et al. Vesiclepedia: a compendium for extracellular vesicles with continuous community annotation. PLoS Biol (2012) 10(12):e1001450. doi:10.1371/journal.pbio.1001450

11. Kim DK, Kang B, Kim OY, Choi DS, Lee J, Kim SR, et al. EVpedia: an integrated database of highthroughput data for systemic analyses of extracellular vesicles. J Extracell Vesicles (2013) 2(2):20384. doi:10.3402/jev.v2i0.20384

12. Baj-Krzyworzeka M, Weglarczyk K, Mytar B, Szatanek R, Baran J, Zembala M. Tumour-derived microvesicles contain interleukin- 8 and modulate production of chemokines by human monocytes. Anticancer Res (2011) 31(4):1329-35.

13. Deregibus MC, Cantaluppi V, Calogero R, Lo Iacono $\mathrm{M}$, Tetta C, Biancone L, et al. Endothelial progenitor cell derived microvesicles activate an angiogenic program in endothelial cells by a horizontal transfer of mRNA. Blood (2007) 110(7):2440-8. doi:10.1182/blood-200703-078709

14. Gibbings DJ, Ciaudo C, Erhardt M, Voinnet O. Multivesicular bodies associate with components of miRNA effector complexes and modulate miRNA activity. Nat Cell Biol (2009) 11(9):1143-9. doi:10.1038/ncb1929

15. Skog J, Würdinger T, van Rijn S, Meijer DH, Gainche L, Sena-Esteves M, et al. Glioblastoma microvesicles transport RNA and proteins that promote tumour growth and provide diagnostic biomarkers. Nat Cell Biol (2008) 10(12):1470-6. doi: $10.1038 /$ ncb 1800

16. Valadi H, Ekström K, Bossios A, Sjöstrand M, Lee JJ, Lötvall JO. Exosome-mediated transfer of mRNAs and microRNAs is a novel mechanism of genetic exchange between cells. Nat Cell Biol (2007) 9(6):654-9. doi:10.1038/ncb1596

17. Mittelbrunn M, Gutiérrez-Vázquez C, VillarroyaBeltri C, González S, Sánchez-Cabo F, González MÁ, et al. Unidirectional transfer of microRNAloaded exosomes from $\mathrm{T}$ cells to antigenpresenting cells. Nat Commun (2011) 2:282. doi: 10.1038/ncomms1285

18. Guescini M, Genedani S, Stocchi V, Agnati LF. Astrocytes and Glioblastoma cells release exosomes carrying mtDNA. J Neural Transm (2009) 117(1):1-4. doi:10.1007/s00702-009-0288-8

19. Ronquist KG, Ronquist G, Carlsson L, Larsson A. Human prostasomes contain chromosomal DNA. Prostate (2009) 69(7):737-43. doi:10.1002/pros. 20921

20. Stoorvogel W, Kleijmeer MJ, Geuze HJ, Raposo G. The biogenesis and functions of exosomes. Traffic (2002) 3(5):321-30. doi:10.1034/j.1600-0854. 2002.30502.x

21. Szostak N, Royo F, Rybarczyk A, Szachniuk M, Blazewicz J, del Sol A, et al. Sorting signal targeting mRNA into hepatic extracellular vesicles. RNA Biol (2014) 11(7):836-44. doi:10.4161/rna.29305

22. Villarroya-Beltri C, Gutiérrez-Vázquez C, SánchezCabo F, Pérez-Hernández D, Vázquez J, MartinCofreces N, et al. Sumoylated hnRNPA2B1 controls the sorting of miRNAs into exosomes through binding to specific motifs. Nat Commun (2013) 4:2980. doi:10.1038/ncomms3980

23. Raimondo F, Morosi L, Chinello C, Magni F, Pitto M. Advances in membranous vesicle and exosome proteomics improving biological understanding and biomarker discovery. Proteomics (2011) 11(4):709-20. doi:10.1002/pmic.201000422

24. El-Serag HB, Rudolph KL. Hepatocellular carcinoma: epidemiology and molecular carcinogenesis. Gastroenterology (2007) 132(7):2557-76. doi: 10.1053/j.gastro.2007.04.061

25. Saenz-Cuesta M, Osorio-Querejeta I, Otaegui D. Extracellular vesicles in multiple sclerosis: what are they telling us? Front Cell Neurosci (2014) 8(100):100. doi: $10.3389 /$ fncel.2014.00100

26. Peinado H, Alečković M, Lavotshkin S, Matei I, Costa-Silva B, Moreno-Bueno G, et al. Melanoma exosomes educate bone marrow progenitor cells toward a pro-metastatic phenotype through MET. Nat Med (2012) 18(6):883-91. doi:10.1038/nm. 2753

27. Yang L, Wu XH, Wang D, Luo CL, Chen LX. Bladder cancer cell-derived exosomes inhibit tumor cell apoptosis and induce cell proliferation in vitro. $\mathrm{Mol}$ Med Rep (2013) 8(4):1272-8. doi:10.3892/mmr. 2013.1634

28. Bellingham SA, Coleman BM, Hill AF. Small RNA deep sequencing reveals a distinct miRNA signature released in exosomes from prioninfected neuronal cells. Nucleic Acids Res (2012) 40(21):10937-49. doi:10.1093/nar/gks832

29. Clayton A, Al-Taei S, Webber J, Mason MD, Tabi Z. Cancer exosomes express CD39 and CD73, which suppress $\mathrm{T}$ cells through adenosine production. J Immunol (2011) 187(2):676-83. doi:10. 4049/jimmunol.1003884

30. Conde-Vancells J, Rodriguez-Suarez E, Embade N, Gil D, Matthiesen R, Valle M, et al. Characterization and comprehensive proteome profiling of exosomes secreted by hepatocytes. J Proteome Res (2008) 7(12):5157-66. doi:10.1021/pr8004887

31. Conde-Vancells J, Gonzalez E, Lu SC, Mato JM, Falcon-Perez JM. Overview of extracellular microvesicles in drug metabolism. Expert Opin Drug Metab Toxicol (2010) 6(5):543-54. doi:10. 1517/17425251003614766

32. Royo F, Falcon-Perez JM. Liver extracellular vesicles in health and disease. J Extracell Vesicles (2012) 1:1-7. doi:10.3402/jev.v1i0.18825

33. Nicholson JK, Lindon JC, Holmes E. 'Metabonomics': understanding the metabolic responses of living systems to pathophysiological stimuli via multivariate statistical analysis of biological NMR spectroscopic data. Xenobiotica (1999) 29(11):1181-9. doi:10.1080/004982599238047

34. Gonzalez E, van Liempd S, Conde-Vancells J, Gutierrez-de Juan V, Perez-Cormenzana M, Mayo $\mathrm{R}$, et al. Serum UPLC-MS/MS metabolic profiling in an experimental model for acute-liver injury reveals potential biomarkers for hepatotoxicity. Metabolomics (2012) 8(6):997-1011. doi:10.1007/ s11306-011-0329-9

35. Dunn WB, Bailey NJ, Johnson HE. Measuring the metabolome: current analytical technologies. Analyst (2005) 130(5):606-25. doi:10.1039/b418288j

36. Novakova L, Solichova D, Solich P. Advantages of ultra performance liquid chromatography over high-performance liquid chromatography: comparison of different analytical approaches 
during analysis of diclofenac gel. J Sep Sci (2006) 29(16):2433-43. doi:10.1002/jssc.200600147

37. Ruiz-Aracama A, Peijnenburg A, Kleinjans J, Jennen D, van Delft J, Hellfrisch C, et al. An untargeted multi-technique metabolomics approach to studying intracellular metabolites of HepG2 cells exposed to 2,3,7,8-tetrachlorodibenzo-p-dioxin. BMC Genomics (2011) 12(251):251. doi:10.1186/ 1471-2164-12-251

38. Mamas M, Dunn WB, Neyses L, Goodacre R. The role of metabolites and metabolomics in clinically applicable biomarkers of disease. Arch Toxicol (2011) 85(1):5-17. doi:10.1007/s00204010-0609-6

39. Barr J, Vázquez-Chantada $\mathrm{M}$, Alonso C, PérezCormenzana M, Mayo R, Galán A, et al. Liquid chromatography-mass spectrometry-based parallel metabolic profiling of human and mouse model serum reveals putative biomarkers associated with the progression of nonalcoholic fatty liver disease. J Proteome Res (2010) 9(9):4501-12. doi:10.1021/ pr1002593

40. Thery C, Amigorena S, Raposo G, Clayton A. Isolation and characterization of exosomes from cell culture supernatants and biological fluids. Curr Protoc Cell Biol (2006) 3:3.22. doi:10.1002/ 0471143030.cb0322s30

Conflict of Interest Statement: The authors declare that the research was conducted in the absence of any commercial or financial relationships that could be construed as a potential conflict of interest.

Received: 20 November 2014; paper pending published: 01 December 2014; accepted: 05 December 2014; published online: 23 December 2014.
Citation: Palomo L, Casal E, Royo F, Cabrera D, van-Liempd S and Falcon-Perez JM (2014) Considerations for applying metabolomics to the analysis of extracellular vesicles. Front. Immunol. 5:651. doi: 10.3389/fimmu.2014.00651

This article was submitted to Inflammation, a section of the journal Frontiers in Immunology.

Copyright $\odot 2014$ Palomo, Casal, Royo, Cabrera, vanLiempd and Falcon-Perez. This is an open-access article distributed under the terms of the Creative Commons Attribution License (CC BY). The use, distribution or reproduction in other forums is permitted, provided the original author(s) or licensor are credited and that the original publication in this journal is cited, in accordance with accepted academic practice. No use, distribution or reproduction is permitted which does not comply with these terms. 